\title{
Reply to the comment on: "Efficiency of bimaxillary advancement surgery in increasing the volume of the upper airways: a systematic review of observational studies and meta-analysis"
}

\author{
Henrique Damian Rosário ${ }^{1}$ Gustavo Mussi Stefan Oliveira ${ }^{2}$ - Irlan Almeida Freires ${ }^{3}$ • \\ Felipe de Souza Matos ${ }^{4}$ Luiz Renato Paranhos ${ }^{5,6}$
}

Received: 24 May 2016/Accepted: 24 May 2016/Published online: 6 June 2016

(C) Springer-Verlag Berlin Heidelberg 2016

First, we would like to thank the author of the letter for taking the time to read the article and evaluate our work. The Letter to Editor correctly indicated that the upper airway is also formed by the nasal cavity and pharynx. We are in agreement with the letter. In fact, the upper airway is normally divided into four anatomic regions: nasopharynx, retropalatal, retroglossal, and hypopharynx. The letter also expressed concern in regard to the interpretation of data. The argument presented was that nasal resistance is a major contributing factor of obstructive sleep apnea (OSA) and that none of the studies included in the systematic review researched nasal cavity volume. The cited study [1] to support this argument was completed in 1964, with a pool of nine subjects. From those, six subjects were used for upper airway resistance, and only four for partitioning respiratory resistance, due to measurement inconsistencies.

This reply refers to the comment available at doi:10.1007/s00405016-4118-y.

Luiz Renato Paranhos

paranhos@ortodontista.com.br

1 Department of Orthodontics, Faculdades Integradas do Norte de Minas-FUNORTE, Florianópolis, SC, Brazil

2 University of Louisville School of Dentistry, Louisville, KY, USA

3 Department of Physiological Sciences, Piracicaba Dental School, University of Campinas, Piracicaba, SP, Brazil

4 Postgraduate Program in Restorative Dentistry, Endodontic Division, State University of São Paulo,

São José dos Campos, SP, Brazil

5 Department of Dentistry, Federal University of Sergipe, Lagarto, SE, Brazil

6 Residencial Vista do Atlântico, Ap. 1402, Jordão de Oliveira St., 996, Atalaia, Aracaju, SE 49037-330, Brazil
Studies published more recently pointed that the majority of patients with OSA present closure sites in the oropharynx, predominantly [2-4]. Nasal obstruction obligates the individual to breathe through the oral cavity, which lengthens and narrows the upper airway [5]. In that respect, it appears to be at least pertinent to understand the efficiency of a specific procedure, bimaxillary advancement surgery, in increasing the volume of the upper airway. This procedure expands the skeletal framework, augmenting the naso and oropharyngeal spaces. Currently, bimaxillary advancement surgery is the most effective surgical treatment for management of OSA in adults [6, 7]. In summary, the authors respectfully disagree with the claim that the interpretation of the data gathered by the present systematic review is imprecise. We believe that the data contained in this article is valuable to the scientific community. Furthermore, and in light of the arguments above, we believe that the title chosen is appropriate and describes well the content of the study.

\section{References}

1. Ferris BG Jr, Mead J, Opie LH (1964) Partitioning of respiratory flow resistance in man. J Appl Physiol 19:653-658

2. Horner RL, Mohiaddin RH, Lowell DG et al (1989) Sites and sizes of fat deposits around the pharynx in obese patients with obstructive sleep apnoea and weight matched controls. Eur Respir J 2:613-622

3. Schwab RJ, Pack AI, Gupta KB et al (1996) Upper airway and soft tissue structural changes induced by CPAP in normal subjects. Am J Respir Crit Care Med 154:1106-1116

4. Suto Y, Matsuo T, Kato T et al (1993) Evaluation of the pharyngeal airway in patients with sleep apnea: value of ultrafast MR imaging. AJR Am J Roentgenol 160:311-314 
5. Lee SH, Choi JH, Shin C et al (2007) How does open-mouth breathing influence upper airway anatomy? Laryngoscope 117:1102-1106

6. Fusetti M, Fioretti AB, Valenti M et al (2012) Cardiovascular and metabolic comorbidities in patients with obstructive sleep apnoea syndrome. Acta Otorhinolaryngol Italica 32:320-325
7. Lye KW, Waite PD, Meara D et al (2008) Quality of life evaluation of maxillo-mandibular advancement surgery for treatment of obstructive sleep apnea. J Oral Maxillofac Surg 66:968-972 